\section{Myths of MTAS and MMC}

As we move ever closer to the start of August, there remains no sign that the MTAS (Medical Training Application Service) debacle will end. In the months since this sorry episode began, doctors have been united in a way never seen before, ${ }^{1}$ and the common goals of those professionals who have invested so much of themselves in the NHS are becoming clearer: a fair, validated and transparent application process for all doctors; an expansion of training numbers combined with rational workforce planning; the preservation of those aspects of training which have made British medicine so respected; and, above all, the best possible care for the people who seek help from their doctor. Despite the apologies and the high-level resignations, ${ }^{2-4}$ the government persists in its efforts to keep the sinking MTAS ship afloat. The Department of Health, its attention focused as ever upon public perception, continues to fight its corner through spin and sound-bite. This makes it important that doctors communicate with the public in a manner that cuts through government rhetoric, to explain how part of the huge financial investment in the NHS is being squandered. In particular, the myth that MTAS is merely a hiccup in an otherwise well thought-out, sensible program of reform-MMC (Modernising Medical Careers) - cannot go unchallenged. With this in mind, we present some of the more prominent myths that continue to abound regarding MTAS and MMC.

\section{MYTH ONE: DOCTORS AND THEIR LEADERS AGREED TO THE DEVELOPMENT OF MMC AND MTAS}

A popular government defence of the MMC and MTAS process is that their development was supported by doctors and their leaders:

'... we have worked closely with the Academy of Royal Medical Colleges, the BMA, NHS Employers and others over a long period.' (Andrew Burnham, Health Minister, 24 April 2007) ${ }^{5}$

Sadly, there is a continuing failure to acknowledge the multiple occasions on which both the Royal Colleges and the BMA have questioned the timing and implementation of the process. In their letter to the Lancet, the Presidents of the Royal College of Physicians and Royal College of Surgeons reported that:

'... the genesis of MMC and the Medical Training Application Service (MTAS) has been complex and the final products far away from the principles of "Unfinished Business". '6

Even more damning is the Royal College of Physicians' assertion that this is: 'the worst episode in the history of medical training in the UK in living memory. ${ }^{17}$

There are many tough challenges ahead, but issues such as the disempowerment of the Royal Colleges with the institution of the government quango PMETB, and in particular the wider concern of excessive central control and deprofessionalization of doctors should provoke apprehension in all within medicine.

\section{MYTH TWO: DOCTORS DO NOT WANT COMPETITION}

That junior doctors are anti-competitive has increasingly become the government mantra in recent weeks. What better way to denigrate objectors' concerns than to invoke an elitist, haughty stereotype, convinced of its right to unimpeded progression? Yet of all the government's arguments this stands out most blatantly as a straw man fallacy: no doctor would expect that job applications would be uncompetitive; indeed the lives of doctors are, from their schooldays, characterized by intense competition. It is the nature of the competition that is in question. Few would argue that the previous system was perfect, or that some minor, well-considered reform was not appropriate; but the previous system was largely meritocratic and, most importantly, produced very good doctors, a point even the Secretary of State for Health seems to agree with:

'(This house) recognises the international reputation for excellence of medical training in the UK.' (Patricia Hewitt, Secretary of State for Health, 24 April 2007) ${ }^{7}$

It was competition in the medical profession that led to the so-called 'lost tribe' of Senior House Officers and the subsequent development of MMC. However, the proposed solution to this problem will only serve to create a new 'lost tribe' of juniors consisting of those unable to secure one of the limited number of training posts or considered too experienced to apply for training posts, such as those undertaking higher degrees. In the past we could choose to be 'lost' in the pursuit of excellence either via research or a broader clinical experience prior to specialization, and it was these experiences which helped develop importantthough less measurable - qualities of a good doctor.

\section{MYTH THREE: NO DOCTORS WILL BE UNEMPLOYED IN AUGUST}

The government has denied that there will be significant unemployment amongst doctors come August. Yet a leaked document from NHS Employers ${ }^{8}$ investigating whether doctors could do volunteer work overseas seems to suggest that, in at least some parts of the Department of Health, concerns have been raised. With so many different numbers floated regarding training posts - figures propped up by the 
inclusion of fixed term specialist training appointments - it has been difficult to escape the impression of obfuscation by the DoH when, astoundingly, nobody seems sure how many expensively trained, dedicated and capable young doctors will actually be without a job. ${ }^{9}$

\section{MYTH FOUR: THE COMPETENCY-BASED TRAINING SYSTEM OF MMC WILL IMPROVE THE QUALITY OF DOCTORS}

It seems self-evident that measuring how 'competent' a doctor is allows poorly-performing doctors to be identified and makes sure that all doctors achieve a certain standard. Of course, what constitutes a 'competent' doctor, how this is best measured, and indeed whether it can be measured, remain entirely different questions. The unvalidated competencies doctors must achieve under MMC, though important, tend to be simplistic things that are easily measured (e.g. the ability to take blood). Are the more complex aspects of what makes a good doctor to be disregarded because they cannot easily be measured? Those less tangible aspects — such as experience, intuition, sound professional judgement, the ability to establish rapport with patients and, perhaps most importantly, caring-are difficult to measure, but historically have been assessed by close, experienced senior colleagues; again, largely successfully. They allow a distinction to be drawn between a very good doctor and merely a competent one, unlike the alternative which tells us only whether a doctor has acquired basic skills or not. The role of the tried and tested Royal College examinations is also being eroded. Furthermore, it seems ludicrous to suggest that decreasing the number of years taken to train doctors to a 'competent' 'consultant' level can be consistent with the reduced hours of training that have resulted from the European Working Time Directive.

\section{MYTH FIVE: MMC IS ABOUT IMPROVING PATIENT CARE}

The government has been keen to stress throughout both the MMC and MTAS fiascos that one of the central aims of implementing change was to improve patient care. It is perhaps surprising, then, how few people with experience of medical training believe that this will occur. ${ }^{1}$ Perhaps the most pressing issue is what will happen in the first week of August. Will we see the largest ever changeover of doctors over a couple of days, or a failure to recruit people in time, resulting in hugely understaffed medical teams? Neither seems an acceptable option for patient care and safety. Yet the government continues to seek to dissociate itself from this disaster waiting to happen, putting the onus instead on individual Trusts:

'Each hospital Trust, and the board of each Trust, has a responsibility to its patients to ensure that on 1 August, or any other day, the right number of the right staff are available to provide safe, high quality care.' (Patricia Hewitt, Secretary of State for Health, 24 April 2007) ${ }^{10}$

But as one consultant has stated in a letter to MPs:

'Trust CEs and MDs are deceiving themselves if they believe that MTAS can now deliver a full complement of Juniors to their workforce on August 1st.' 11

The clear outcome of MMC and MTAS is to have politicized an entire generation of doctors. More tragically, they risk stifling the vocation of young professionals who, as enthusiastic, ambitious and caring as their predecessors ever were, are faced with unemployment, emigration, or at best a shorter, inferior training experience. There are solutions to this problem, but they do not lie in a doctrinaire DoH championing an arbitrary, iniquitous, unvalidated application process. Perhaps a short bridging period where only non-training posts are awarded would allow service provision while a fair application process is developed. It is important, however, that the delay before any new process is implemented be minimized-junior doctors and the public deserve better.

It seems clear that we cannot remain apolitical when it comes to government health policy. That doctors have found a voice so quickly is due not only to the strength of feeling, but also to the work of Remedy UK, the fledgling group of junior doctors who have so successfully organized the opposition to MMC/MTAS through the march, parliamentary lobby and judicial review. We must unite as doctors to send a clear message to the new Prime Minister and his government: we want to provide the best care for patients that we possibly can, and MMC in its present guise will not allow us to do so.

Competing interests None declared.

\section{Jonathan D Rohrer, Jonathan Kennedy and William D Knight}

Clinical Research Fellows in Neurology, Dementia Research Centre, Institute of Neurology, Queen Square, London WC1N 3BG, UK Correspondence to: Dr Jonathan Rohrer

Email: rohrer@dementia.ion.ucl.ac.uk

\section{REFERENCES}

1 Telegraph. Angry doctors to march over selection crisis. 17 March 2007. Available at http://www.telegraph.co.uk/news/main.jhtml?xml=/ news / 2007/03/16/nmarch116.xml

2 Telegraph. Hewitt apologises over training chaos. 17 April 2007. Available at http://www.telegraph.co.uk/news/main.jhtml?xml=/news/2007/ 04/17/nhealth317.xml

3 Telegraph. Expert in charge of doctors' job fiasco resigns. 31 March 2007. Available at http://www.telegraph.co.uk/news/main.jhtml?xml=/ news $/ 2007 / 03 / 31 /$ nhs231.xml 
4 Ribeiro B. MTAS resignations: implications for MMC. Ann R Coll Surg Engl 2007;89(Suppl.):154-155

5 Hansard. 24 April 2007: Column 847. Available at http:// www.publications.parliament.uk/pa/cm200607/cmhansrd/ cm070424/debtext/70424-0012.htm

6 Gilmore I, Ribeiro B. Modernising Medical Careers: a response from two Presidents of The Royal Colleges. Lancet 2007;369:1513

7 Hansard. 24 April 2007: column 808. Available at http:// www.publications.parliament.uk/pa/cm200607/cmhansrd/ cm070424/debtext/70424-0006.htm

8 Channel 4. Junior doctors to work overseas? 20 April 2007. Available at http://www.channel4.com/news/articles/society/health/junior+ doctors + to + work+overseas $/ 453047$

9 Nicholl DJ. All the President's Men and MMC. Lancet 2007; online 1 May

10 Hansard. 24 April 2007: column 814. Available at http:// www.publications.parliament.uk/pa/cm200607/cmhansrd/cm070424/ debtext/70424-0007.htm

11 DoctorsNet Forum. Dr Gordon Caldwell. 2 May 2007. Available at http://www.doctors.net.uk/Forum/viewPost.aspx?forum_id=273\& post_id $=2232691$

\section{Changing disease patterns in South Asians in the UK}

Cancer is perceived to be a low priority public health issue in South Asians. Yet changing lifestyles and environments towards those of the majority population are shifting epidemiological patterns. Similar patterns will occur in other disease areas. Lack of community awareness of these changes will result in increased exposure to risk factors, poor uptake in screening and delayed clinical presentation.

The UK's South Asian population, the largest minority ethnic group at $4 \%$ of the total population, ${ }^{1}$ are known to have an elevated risk of coronary artery disease-hence research on ethnic differences in disease has concentrated on this area. ${ }^{2}$ In contrast, South Asians have a lower incidence of cancer than the general population, with standardised incidence ratios (SIRs) of all malignant neoplasms reported as $68 \%$ lower in males and $48 \%$ lower in females, ${ }^{3}$ whilst standardised mortality ratios for all cancers have been reported between 58 in Indian men at their best to 85 at their worst in Bangladeshi men. ${ }^{4}$

\section{An epidemiological transition}

Economic development has resulted in an increased uptake of sedentary habits, tobacco use and high-fat diets, leading to the concept of the epidemiological transition as originally described by Omran. ${ }^{5}$ Increasing adoption of the detrimental aspects of the developed world lifestyle is resulting in a shift of epidemiological patterns of cancers in South majority population. Rates of cancer in South Asians in England, though lower than rates in the rest of the English population, are higher than rates in the Indian subcontinent. ${ }^{6}$ The incidence of breast cancer is increasing in South Asians, ${ }^{7}$ and although lung cancer mortality is lower among most South Asian populations than the general population of England and Wales, it is the most common cancer among South Asian men and its incidence is on the increase. ${ }^{8}$

Health protection around cancer in South Asians has focused on ethnic-specific issues such as the increased risk of oral cancer from bidi smoking and chewing tobacco, habits which are prevalent in some South Asian communities, ${ }^{9}$ and liver cancer due to the increased prevalence of hepatitis B in this ethnic group. ${ }^{6}$ However, the most common cancers in ethnic minorities are now the same as those of the general population-breast cancer is the most common malignancy among female South Asians and lung cancer the most common malignancy among male South Asians in the UK. ${ }^{10}$ All-cancer mortality in South Asian migrants has been found to increase with duration of residence in England and Wales, even after adjusting for socio-economic position. ${ }^{11}$ If lung cancer mortality reflects smoking habits of populations 20-30 years previously, as has been proposed, ${ }^{3}$ the likely progression from contemporary behavioural changes to future incidence and mortality data is all too predictable.

\section{Worse access to health care}

Though smoking rates in ethnic minorities remain overall relatively lower than in the majority population, it is of great concern that $43 \%$ of Bangladeshi men smoke compared to the national average of $27 \% .^{8}$ Yet despite high levels of motivation to quit, Bangladeshis have been found to tend to rely on willpower rather than health service interventions, resulting in poor quit rates, ${ }^{12}$ whilst ethnic minority patients were significantly less likely to receive advice on smoking cessation in one study. ${ }^{13}$ Much of the UK Bangladeshi community are classified as having low socioeconomic status, high rates of unemployment and low levels of formal female employment, ${ }^{14}$ and with higher smoking rates being found in inner-city ethnic minority communities, ${ }^{15}$ the finding that those in higher social classes have higher quit rates ${ }^{16}$ is a further source of inequity.

Differential uptake rates for screening by ethnic group have also been reported. One pilot study on uptake of colorectal screening for ethnic groups reported significantly lower rates amongst South Asians, ${ }^{17}$ despite increasing developed world influences on dietary patterns. ${ }^{18}$ Different groups are characterized by different dietary patterns, but such patterns are not permanent, being influenced by the background cultural environment. With the introduction of mass screening in the UK for colorectal cancer, uptake in all minority ethnic groups needs to be monitored and reasons for any differential uptake rates observed investigated. 


\section{Implications for public health}

The tendency to emphasise the importance of cancers such as those of the head and neck among South Asians (because those cancers are relatively more common than in the majority UK population) ignores the wider picture of absolute numbers of cancer cases. ${ }^{10}$ Cancer is used an example here, but there will be other examples of disease areas where, with increased time since migration and increasing life expectancy amongst ethnic minorities, disease patterns will start to resemble that of the majority population. This was highlighted over 10 years ago. ${ }^{19}$ Community awareness of this shift in epidemiology and access to appropriate preventive and curative services for them needs to improve.

As early signs of changing mortality patterns appear amongst ethnic minorities with acculturation, and with behavioural changes (such as smoking uptake) predating mortality changes by 20-30 years, waiting for rigorous mortality data for ethnic minorities may be less important than implementing health protection programmes now to include all ethnic minorities. A piecemeal approach similar to that applied to reducing smoking (spanning nearly half a century from the seminal study by Doll and Hill in 1950 to the first comprehensive preventive strategy, the government white paper 'Smoking Kills' ${ }^{20}$ ) must be avoided. For cancer, knowledge dissemination both within the medical and lay ethnic community should focus on prevention through lifestyle and diet, and earlier detection through better awareness of symptoms and the need to seek medical advice early. If indeed the current low rates of cancer in ethnic groups such as South Asians are likely to increase with behavioural changes, then health protection targeting those behaviours should increase too.

Competing interests MJSZ is a Trustee for the South Asian Health Foundation; PM declares no competing interests.

Funding None.

Guarantor MJSZ is a guarantor for the work and accepts full responsibility for the work and controlled the decision to publish.

Acknowledgments Thanks to Professor Michel Coleman for critically reviewing the manuscript

\section{Dr M Justin S Zaman ${ }^{1}$ and Dr Punam Mangtani ${ }^{2}$}

${ }^{1}$ Clinical Research Fellow in Epidemiology, University College London, 1-19 Torrington Place, London WC1E 6BT, UK

${ }^{2}$ Senior Lecturer in Epidemiology, London School of Hygiene and Tropical Medicine, Keppel Street, London WC1E 7HT, UK Correspondence to: M J S Zaman

E-mail: j.zaman@ucl.ac.uk

\section{REFERENCES}

1 Census. Ethnicity: Population Size. London: Office for National Statistics, 2003

2 McKeigue PM, Miller GJ, Marmot MG. Coronary heart disease in south Asians overseas: a review. J Clin Epidemiol 1989;42:597-609

3 Harding S, Rosato M. Cancer incidence among first generation Scottish, Irish, West Indian and South Asian migrants living in England and Wales. Ethn Health 1999;4:83-92

4 Wild SH, Fischbacher CM, Brock A, Griffiths C, Bhopal R. Mortality from all cancers and lung, colorectal, breast and prostate cancer by country of birth in England and Wales, 2001-2003. Br J Cancer 2006;94:1079-85

5 Omran AR. The epidemiologic transition. A theory of the epidemiology of population change. Milbank Mem Fund $Q$ 1971;49:509-38

6 Winter H, Cheng KK, Cummins C, Maric R, Silcocks P, Varghese C. Cancer incidence in the south Asian population of England (1990-92). Br J Cancer 1999;79:645-54

7 Velikova G, Booth L, Johnston C, Forman D, Selby P. Breast cancer outcomes in South Asian population of West Yorkshire. Br J Cancer 2004;90:1926-32

8 Smith LK, Peake MD, Botha JL. Recent changes in lung cancer incidence for south Asians: a population based register study. BMJ 2003;326:81-82

9 Rahman M, Sakamoto J, Fukui T. Bidi smoking and oral cancer: a meta-analysis. Int J Cancer 2003;106:600-4

10 Bhopal RS, Rankin J. Cancer in minority ethnic populations: priorities from epidemiological data. Br J Cancer 1996;29(Suppl):S22-S32

11 Harding S. Mortality of migrants from the Indian subcontinent to England and Wales: effect of duration of residence. Epidemiology 2003; 14:287-92

12 White M, Bush J, Kai J, Bhopal R, Rankin J. Quitting smoking and experience of smoking cessation interventions among UK Bangladeshi and Pakistani adults: the views of community members and health professionals. J Epidemiol Community Health 2006;60:405-11

13 Stewart A, Rao J, Osho-Williams G, Fairfield M, Ahmad R. Audit of primary care angina management in Sandwell, England. $J$ R Soc Health 2002;122:112-17

14 Eade J, Vamplew T, Peach C. The Bangladeshis: the encapsulated community. In: Peach C (ed). Ethnicity in the 1991 Census. London: HMSO, 1996:150-60

15 Modhood. Ethnic Minorities in Britain: Diversity and Disadvantage. Fourth National Survey of Ethnic Minorities. London: Policy Studies Institute, 1997

16 Jefferis BJMH, Power C, Graham H, Manor O. Changing social gradients in cigarette smoking and cessation over two decades of adult follow-up in a British birth cohort. J Public Health 2004;26:13-18

17 The UK CRC Screening Pilot Evaluation (Ethnicity) Team. Ethnicity: UK Colorectal Cancer Screening Pilot. Warwick: University of Warwick, 2003

18 Black and Minority Ethnic Groups in England: The Second Health and Lifestyle Survey. London: Health Education Authority, 2000

19 Bahl V. Cancer and ethnic minorities - the Department of Health's perspective. Br J Cancer 1996;29(Suppl):S2-S10

20 McNeill A, Raw M, Whybrow J, Bailey P. A national strategy for smoking cessation treatment in England. Addiction 2005;100(S2): 1-11 